Supporting Information for ic051431r

\title{
Dehydrogenative Silane Coupling on Silicon Surfaces via Early Transition Metal Catalysts
}

\section{Yun-Hui Li and Jillian M. Buriak*}

Department of Chemistry, University of Alberta, and the National Institute for Nanotechnology, National Research Council, Edmonton, AB T6G 2G2

Figure S1. Transmission FTIR spectra: (a) porous silicon surfaces prepared via the zirconocene-based system of phenylsilane, (b) neat phenylsilane, (c) porous silicon surfaces prepared via the zirconocenebased system of n-hexylsilane, (d) neat n-hexylsilane.

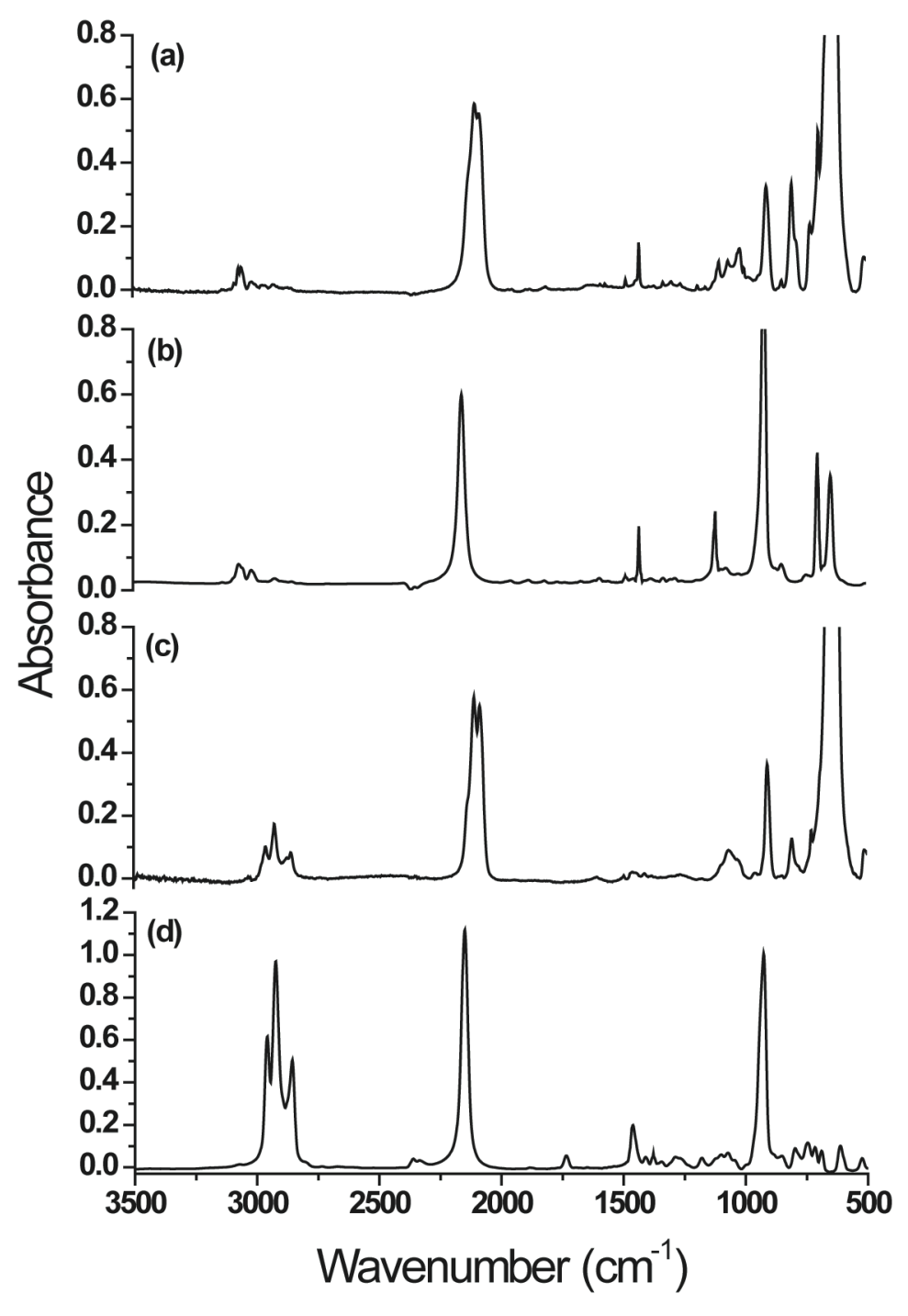


Figure S2. Transmission FTIR spectra of (a) poly(4-fluorophenyl)silane, (b) poly(phenylsilane), (c) poly(n-hexylsilane), (d) poly(n-octadecylsilane).

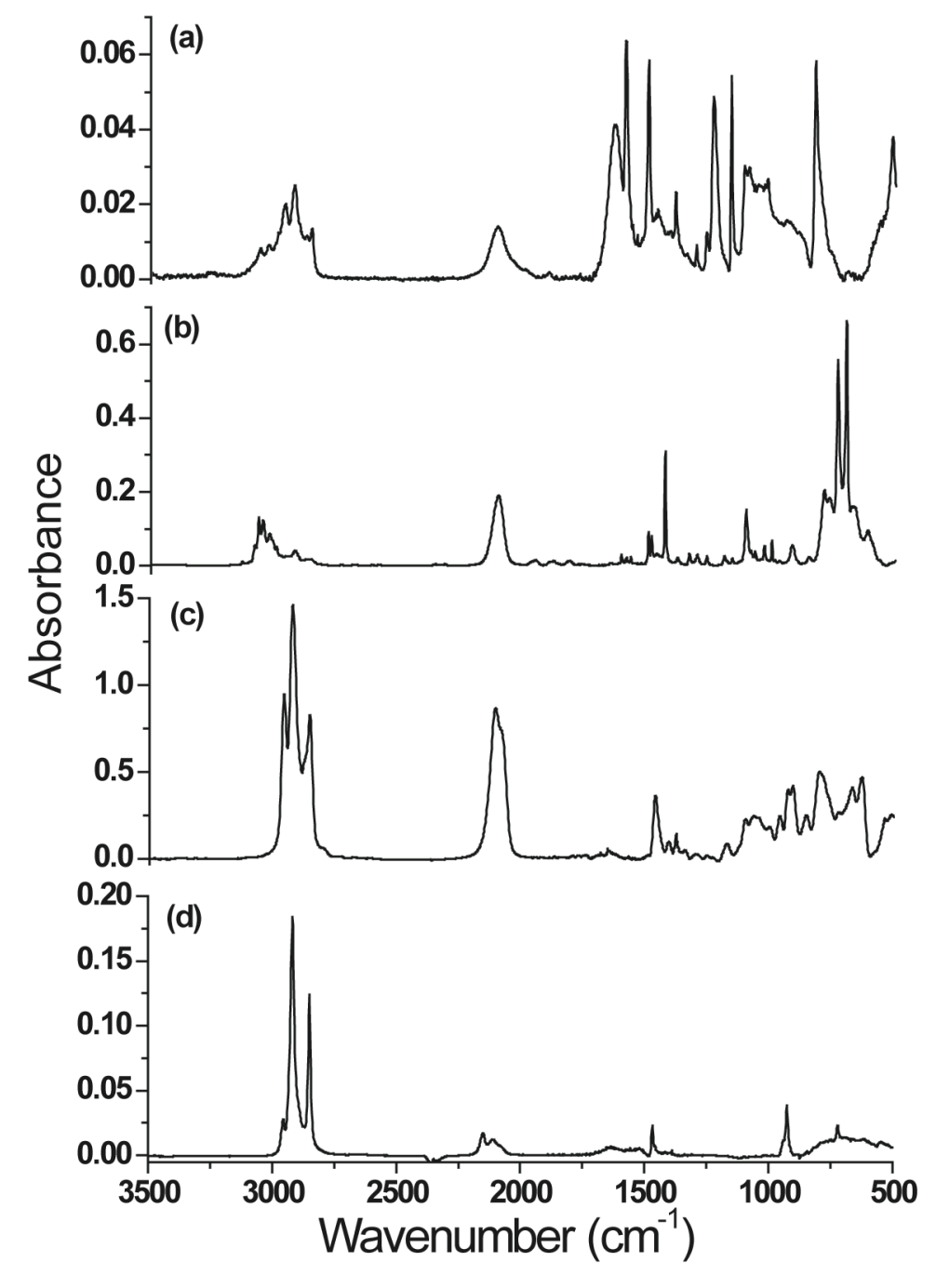


Figure S3. XPS spectra of (a) F 1s region and (b) Si 2p region for a hydride-terminated Si(100) surfaces functionalized with 4-fluorophenylsilane with the zirconocene-based catalyst.
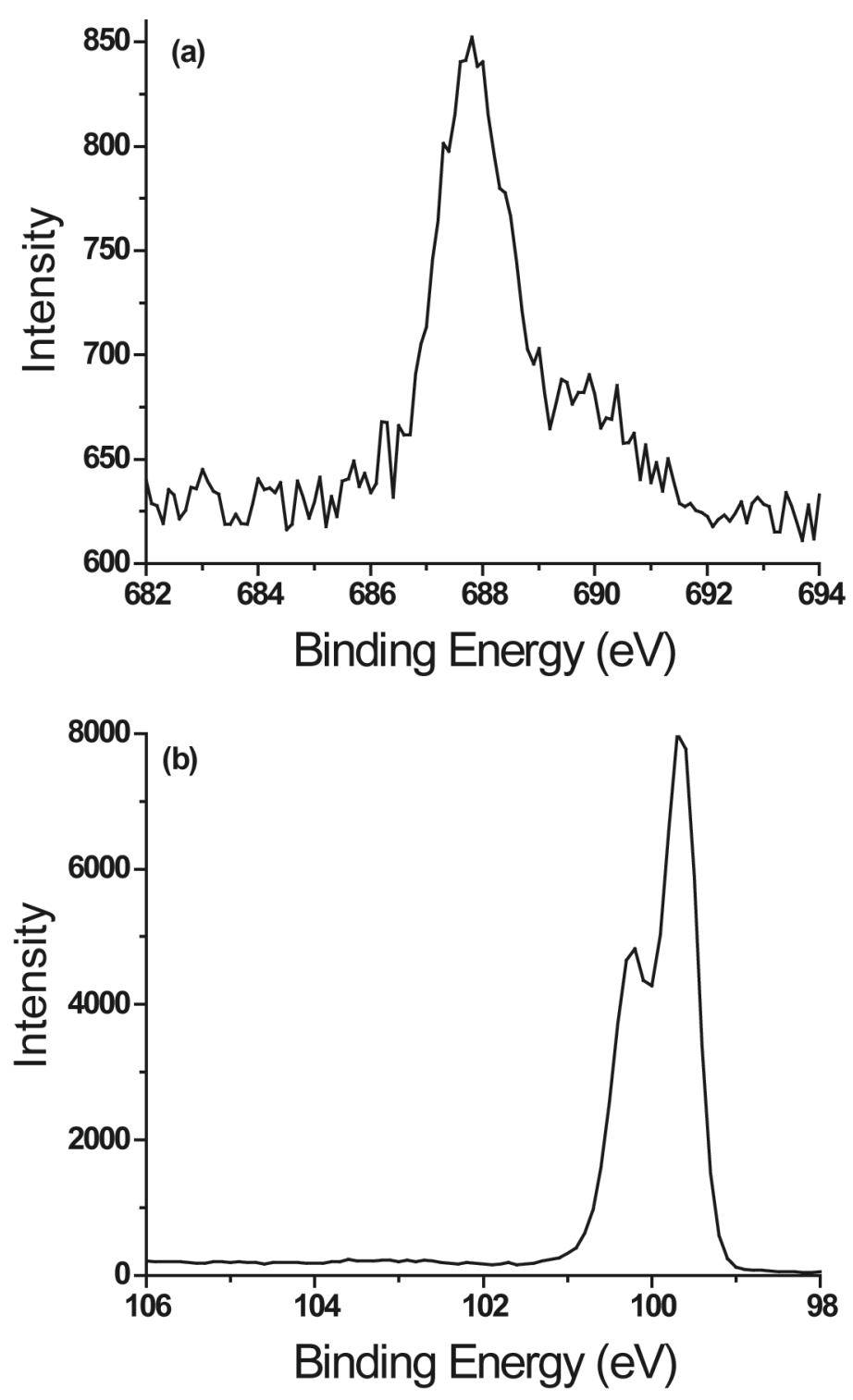
Figure S4. Control experiment corresponding to Figure 4 in the main text - the silicon was exposed to the silane in absence of catalyst. The hydride-terminated surface was treated in an identical manner: A $1 \mathrm{~cm}^{2}$ sample of $\mathrm{Si}(100)-\mathrm{H}_{2}$ was treated with $16 \mu \mathrm{l}$ of phenylsilane in $40 \mu \mathrm{l}$ toluene, allowed to sit for 24 $\mathrm{h}$, and gently rubbed with a cotton swab dipped sequentially in toluene and ethanol. The scan force is $130 \mathrm{nN}$. Scan size $2 \mu \mathrm{m} \times 2 \mu \mathrm{m})$.
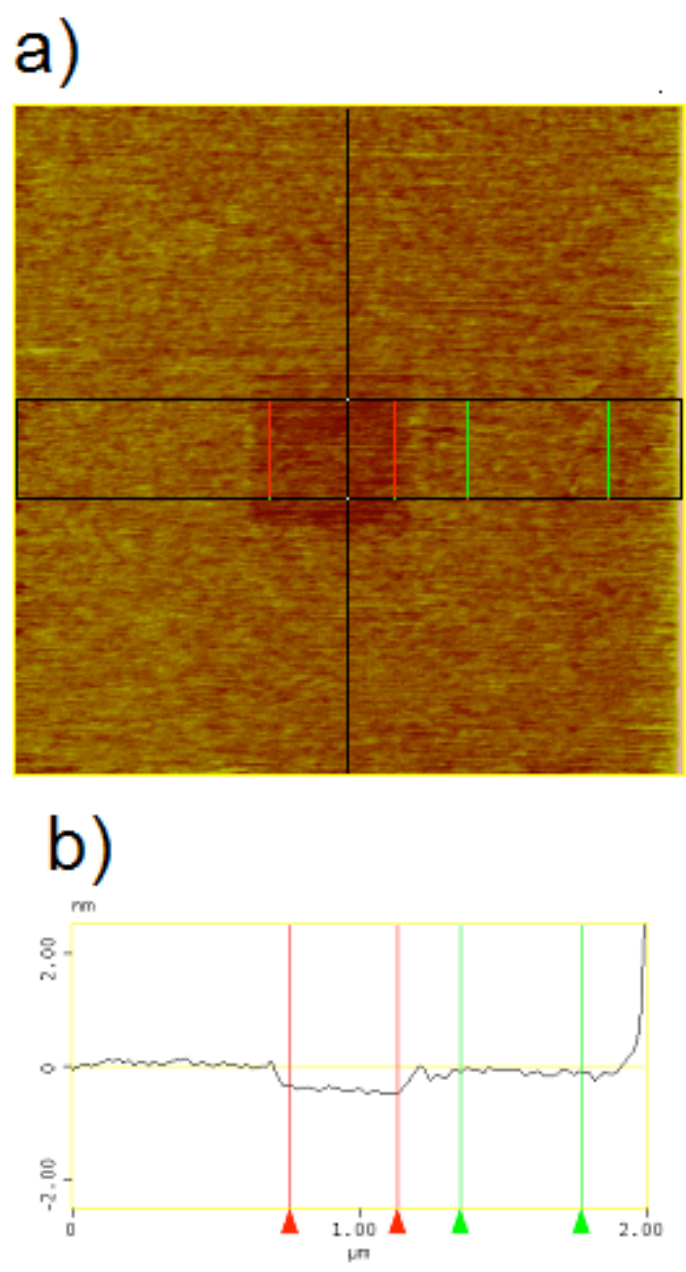
Figure S5. Transmission FTIR spectra of (a) porous silicon functionalized with dodecenyl termination (prepared via Lewis acid mediated hydrosilylation of 1-dodecyne), (b) dehydrogenative phenylsilane coupling on (a), followed by rinsing with toluene and ethanol. The Lewis acid mediated hydrosilylation was carried out as described in references $1 \mathrm{c}$ and 13a of the main text.

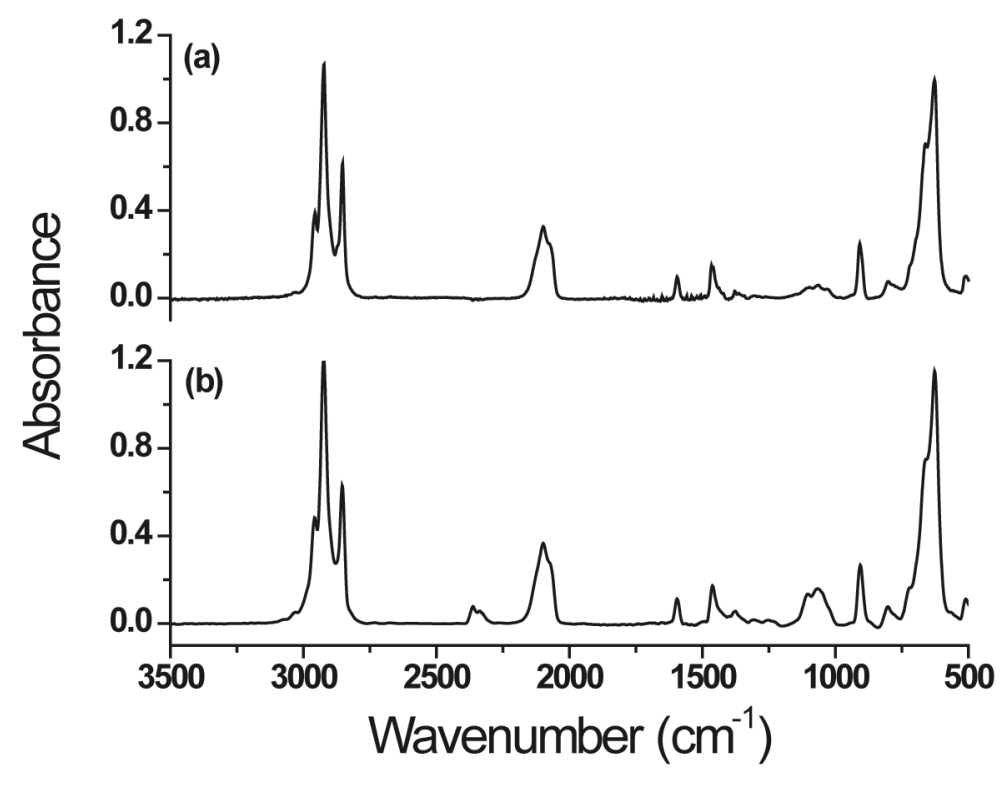

Figure S6. Transmission FTIR spectra of (a) porous silicon functionalized with styrenyl termination (prepared via Lewis acid mediated hydrosilylation of phenylacetylene, references 1c and 13a of main text), (b) dehydrogenative n-octadecylsilane coupling on (a), followed by rinsing with toluene and ethanol.

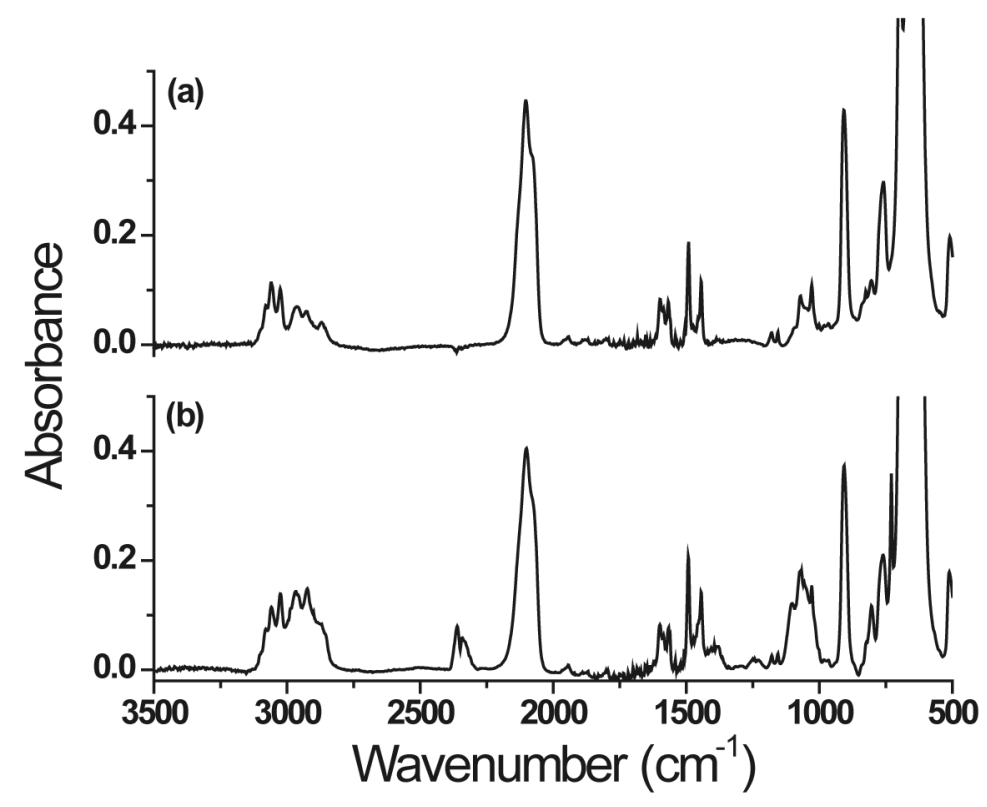


Figure S7. Transmission FTIR spectra of (a) dropping of poly(phenylsilane) on a porous silicon surface and allowed to dry and sit for $24 \mathrm{~h}$ in the glovebox; (b) sample of (a) rinsed with toluene and ethanol.

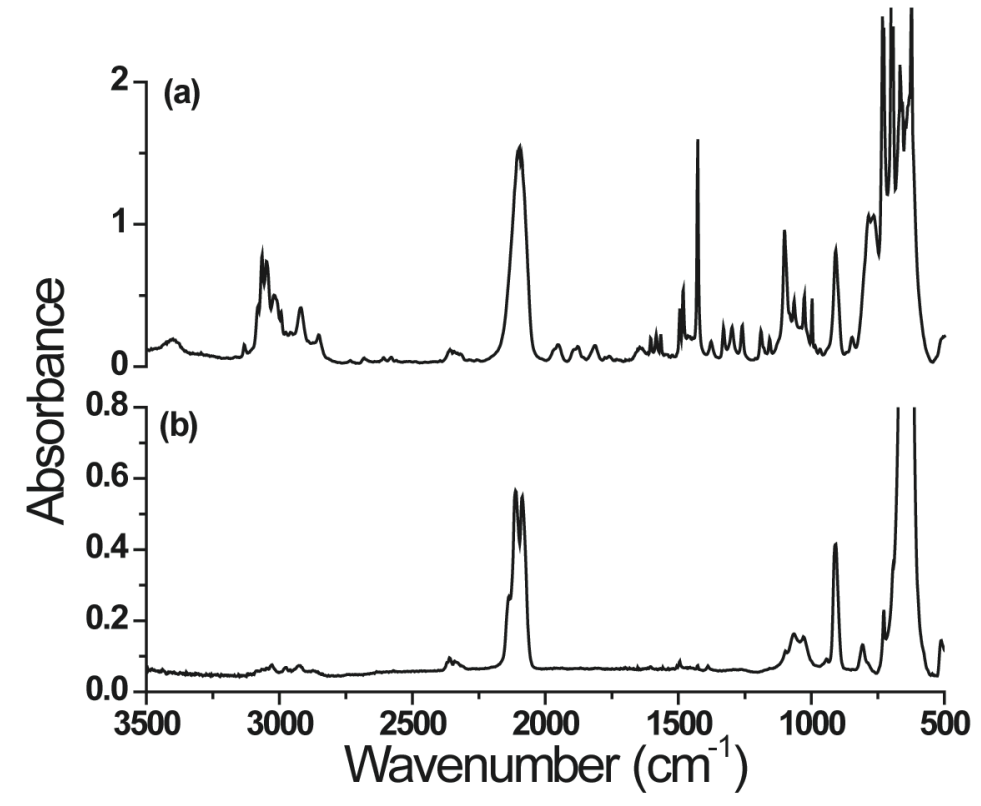

Figure S8. Transmission FTIR spectra of (a) dropping of poly(n-octadecylsilane) on a porous silicon surface and allowed to dry and sit for $24 \mathrm{~h}$ in the glovebox, (b) sample of (a) rinsed with toluene and ethanol.

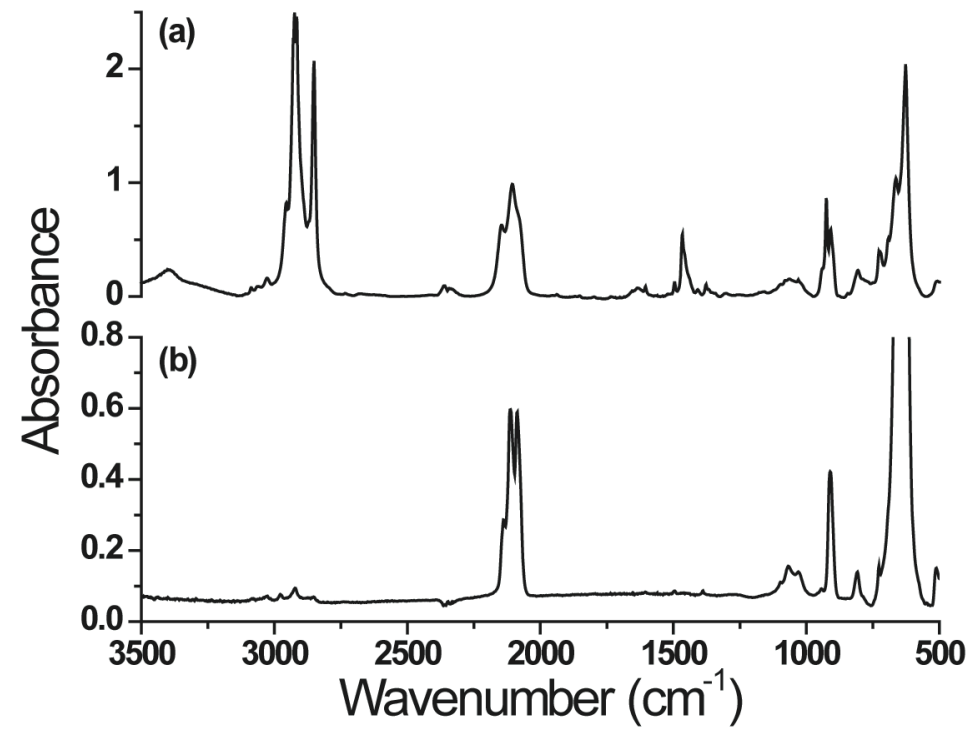


Figure S9. Transmission FTIR spectra of (a) porous silicon surface treated exclusively with the zirconocene-based catalyst (no silane) - the conditions were identical to those described in the main text, with the exception that no silane was added. (b) porous silicon surface treated with pre-prepared poly(noctadecylsilane) (10 $\mu \mathrm{l}$ of silane in $50 \mu \mathrm{l}$ of toluene) and the zirconocene-based catalyst (standard amount), (c) porous silicon surface treated with pre-prepared poly(phenylsilane) (10 $\mu \mathrm{l}$ of silane in $50 \mu \mathrm{l}$ of toluene) and the zirconocene-based catalyst (standard amount). All samples were rinsed with toluene and ethanol.

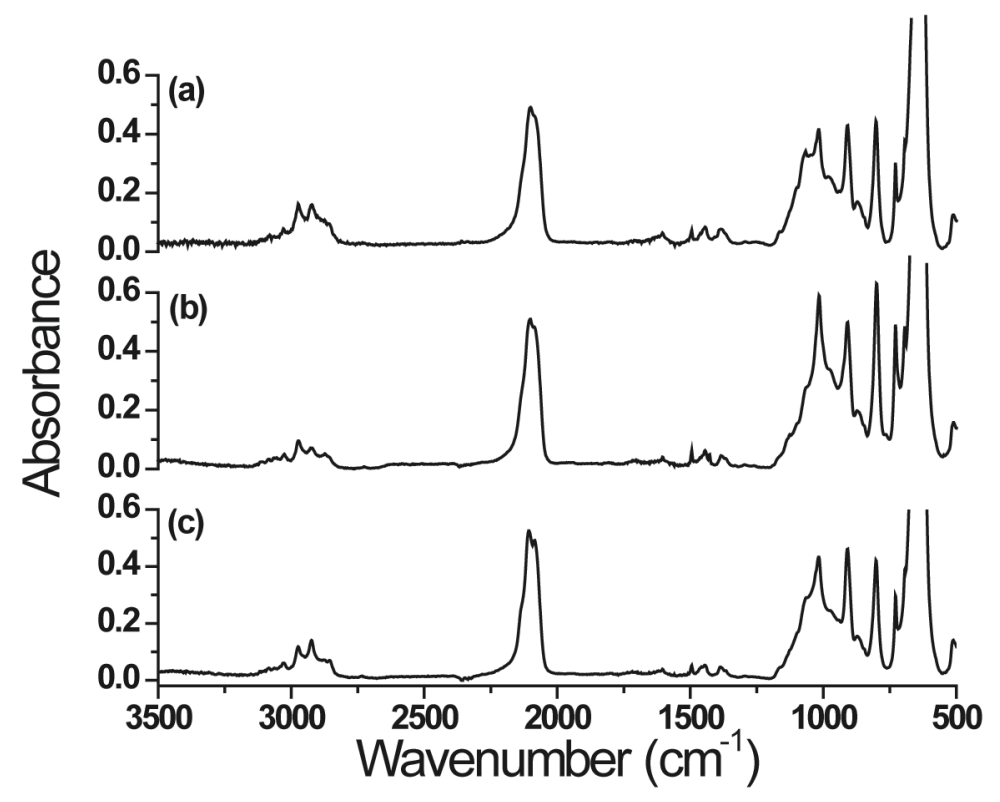

